\title{
Cidades Saudáveis, estratégias e desafios em novos tempos
}

Dossier de PESQuisa : CidAde SAUdÁvel

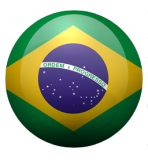

\section{Márcia Faria Westphal}

Professora Titular Sênior, Faculdade de Saúde Pública da Universidade de São Paulo, Pesquisadora do Centro de Estudos, Pesquisa e Documentação em Cidades Saudáveis (CEPEDOC). São Paulo [SP], Brasil <marciafw@terra.com.br>.

\section{Resumo}

Neste artigo apresentamos uma estratégia de desenvolvimento local - Cidades Saudáveis que tem sido praticada em alguns municípios e regiões do país, desde os anos de 1990. 0 objetivo é apresentar um modelo de desenvolvimento local - Cidades Saudáveis que já tem sido assumido por vários municípios do país desde 1990, que associado a novas agendas com as quais o país tem se comprometido, possa ajudar o país a superar a crise política, econômica e de valores que está vivendo, enfrentar o processo de urbanização crescente e superar o aumento das iniquidades que tem dificultado a vida da população que ocupa e trabalha nas grandes, médias e pequenas cidades. 0 movimento por Cidades Saudáveis tem sido fomentado e experimentado no país desde finais da década de 80 , com sucesso em algumas regiões do país. 0 modelo é reapresentado, com todas as suas caraterísticas e aventada a possibilidade de formar redes de municípios, que se ajudem mutuamente e deem força a novos projetos. Novas agendas da Organização das Nações Unidas, como os Objetivos do Desenvolvimento do Milênio, com a qual o Governo Brasileiro esteve comprometido e que foi finalizada com êxito em 2014, envolveu municípios brasileiros como um compromisso local e do país e seus indicadores serviram como base para avaliação de projetos de Cidades Saudáveis e Agenda 21 ao seu final. Agora nova agenda e novo compromisso com os Objetivos do Desenvolvimento Sustentado, foram assumidos pelo país que se comprometeu a atingir metas até 2030. Mais de 200 prefeitos, indicados pela Associação dos Prefeitos, já assinaram um termo de compromisso da sua administração com os Objetivos do Desenvolvimento Sustentado, incluindo-se entre os municípios inseridos no programa de Cidades Sustentáveis. Nesta época de mudanças esse artigo pode ajudar os interessados a encontrar apoios teórico e práticos visando novos rumos para o desenvolvimento de agendas que indiquem caminhos para diminuir as iniquidades e melhorar a qualidade de vida e saúde da população.

\section{Palavras-chave}

Cidades Saudáveis. Estratégias. Promoção da saúde. Desigualdade.

\section{Healthy Cities, strategies and challenges in the new times}

\begin{abstract}
In this article, we present a strategy of local development - Healthy Cities that has been practiced in some municipalities and regions of the country since the 1990s. The objective is to present a model of local development - Healthy Cities that has already been assumed by several municipalities of the country, since 1990, which, together with new agendas with which the country has committed itself, can help the country overcome the political, economic and values crisis it is experiencing, face the growing urbanization process and overcome the growing inequities that have made it difficult the life of the population that occupies and works in large, medium and small cities. The movement for Healthy Cities has been fostered and experimented in the country since the end of the 1980s with success in some regions of the country. The model is represented, with all its characteristics and the possibility of forming networks of municipalities that help each other and give strength to new projects. New United Nations agendas such as the Millennium Development Goals, with which the Brazilian Government was committed and which was successfully completed in 2014, involved Brazilian municipalities as a local and country commitment and their indicators served as a basis for evaluation of Healthy Cities projects and Agenda 21 to its end. Now a new agenda and new commitment to the Goals of Sustained Development have been assumed by the country that has committed itself to achieving goals by 2030. More than 200 mayors, appointed by the Association of Mayors, have already signed a term of commitment of their administration with the Goals of Sustainable Development, including among the municipalities included in the Sustainable Cities program. In this time of change this article can help those interested to find new practical theoretical support to find directions for the development of agendas that indicate ways to reduce inequities and improve the quality of life and health of the population.
\end{abstract}

\section{Keywords}

Healthy Cities. Strategies. Health promotion. Inequities. 


\section{Introdução}

Nós estamos no ano 2018 e o Brasil acaba de eleger um novo presidente, de características conservadoras e que pretende com alguns de seus ministros estimular a economia através de uma proposta liberal e resolver o problema da corrupção endêmica e da violência intensificando ações cognominadas de "Lava Jato" e com grande parte da sua população a margem do processo de desenvolvimento.

Brasil, continua sendo um país de privações com necessidades e dificuldades desigualmente distribuídas na proporção inversa das condições socioeconômicas de suas famílias, fazendo que grande parte da sua população viva a margem do processo de desenvolvimento. 0 Produto Interno Bruto (PIB) ainda que não pequeno comparado a outros países não está crescendo como se esperava, especialmente depois que uma crise política que em 2015 se instaurou fortemente, a partir do impedimento da presidente em exercício (Wikipedia, 2018).

Partindo do princípio que a quantidade de riqueza gerada por uma sociedade é um elemento fundamental para a melhoria das condições de vida, de saúde, é importante demonstrar que os problemas que o Brasil atravessa se relacionam a um conjunto complexo de causas relacionadas ao modelo de desenvolvimento em vigência.

Uma consequência imediata no modelo de desenvolvimento adotado promove as iniquidades, que tem impactado as condições ambientais, condições de vida, saúde, como, por exemplo, falta de água, uso inadequado do solo, saneamento básico e outros, que acabam prejudicando a saúde das pessoas.

Outra questão importante é que o processo de urbanização no país que concomitante com a globalização tem sido intenso nos últimos 70 anos, passando o percentual total da população que vive nas cidades de 45\% em 1945 (45 milhões) para 85\% (175 milhões) de acordo com os resultados do censo demográfico de 2010, com uma projeção grande de crescimento para 2050, chegando a mais de $200 \%$. Vide gráfico 1 elaborado com dados do Censo de 2010, que comprovam a ocorrência desse processo de inversão da distribuição da população brasileira entre a zona rural e urbana no Brasil de 1950 a 2010.

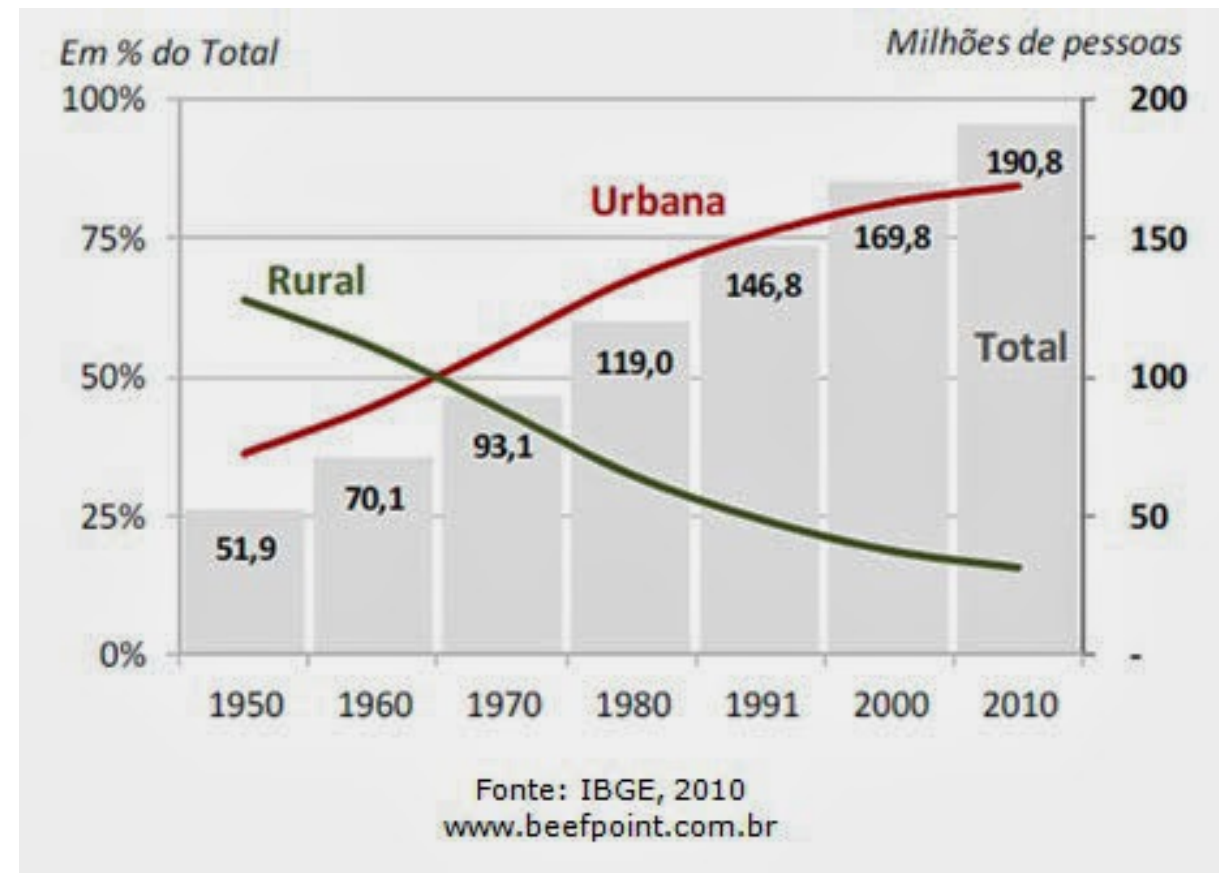

Gráfico 1: Porcentagem de população rural e urbana no Brasil dos anos 1950 a 2010

As cidades, nesse processo de globalização, de modo geral, e as brasileiras de modo especial, refletem espaços globais de privilégio e exclusão, orientando um modelo obsoleto e irracional de 
ocupação do espaço urbano, promovendo a migração e a concentração da população nas grandes metrópoles. 0 que assistimos na grande maioria das cidades brasileiras atualmente é um quadro desolador de perda de identidade entre as pessoas e o espaço geográfico a que pertencem, grande fragmentação e segregação socioespacial, iniquidades no acesso à terra urbanizada e a moradia saudável, segura e legal, ao saneamento ambiental, aos transportes públicos de qualidade e poluição do ar, à educação, ao emprego e aos serviços de saúde. (Westphal, Mendes \& Comaru, 2006; Westphal \& Costa Oliveira, 2015).

Dadas as carências, demandas e déficits gigantescos existentes nas cidades brasileiras, o caminho a percorrer é bastante longo, sobretudo considerando a dificuldade de articulação entre os diferentes setores do governo, a escassez de recursos disponibilizados para setores que necessitam de investimentos orçamentários e subsidiados como saúde, educação, habitação, saneamento e transportes públicos urbanos

Um projeto de desenvolvimento de Cidades, em um país essencialmente urbano, pode ser uma ajuda importante, mas precisa do compromisso do governo local e da sociedade civil em identificar e equacionar potencialidades locais, para a superação de dificuldades e problemas. Existem hoje, no Brasil, 16 aglomerações urbanas com mais de 1 milhão de habitantes cada, lideradas pelas megametrópoles de São Paulo e Rio de janeiro, mas seguidas por várias outras. Tal concentração populacional, sem o correspondente crescimento da oferta de infraestrutura física (moradias, saneamento, transporte público), social (educação, saúde, lazer), emprego e renda, leva parte da população a viver em condições precárias, em favelas ou outras formas de assentamento onde prolifera a miséria e a degradação humana e o crime organizado, esse último, trazendo para perto das pessoas a violência (Westphal \& Oliveira, 2017).

Completando esse cenário de problemas temos a mobilidade das pessoas dentro das cidades. Muitos demoram mais de 2 horas para se locomoverem de suas moradias para o local de trabalho, escola e outros, ou seja, esse deslocamento precisa ser reprogramado. Há, portanto, perfis diferentes de população formando grupos com diferentes tipos de problemas. Algumas formam grupos inseridos no contexto mais amplo e outras formas de comunidades isoladas e prejudicadas por terem como desafio a ser enfrentado "o conviver com as dificuldades".

Na tentativa de mensurar estas desigualdades, no ano de 2017, Comissão Econômica das Nações Unidas para América Latina e Caribe (CEPAL), calculou o Coeficiente de Gini - Indice internacional que mede as desigualdades sociais e o nível de concentração de renda - para rendimentos pessoais. 0 valor médio obtido para 17 países da América Latina, foi de 0,469, o que levou os técnicos internacionais a concluir que "os níveis de desigualdade na região são muito altos" (Agência Brasil, 2017).

Frente a todas as dificuldades de gestão e as desigualdades encontradas no mundo, e em particular na América Latina e Brasil, intelectuais ligados a teoria política promovem a discussão sobre "desigualdade justa", para analisar o conceito de equidade. Para Whitehead (1990), a grande especialista da saúde nesta área de conhecimento, iniquidades sociais entre grupos e indivíduos são as desigualdades que, além de sistemáticas e relevantes são também evitáveis, injustas e desnecessárias. Em sua abordagem da equidade, quando se refere às diferenças evitáveis e desnecessárias e que também podem ser consideradas injustas, a autora destaca a dimensão ética e moral, chamando atenção para o fato que as grandes iniquidades alteram as condições sociais e de saúde e o acesso aos serviços correspondentes (Westphal, 2007).

Várias ações tem sido feitas para o enfrentamento das iniquidades e os problemas acarretados pela concentração de população nas cidades, dentre elas o surgimento e implementação de agendas sociais como a de Cidades Saudáveis e hoje em função do compromisso do nosso governo com os Objetivos dos Desenvolvimento Sustentável, e com a agenda da Organização das Nações Unidas, que os incorpora - de Cidades Sustentáveis, tendo como pano de fundo as concepções de Promoção da Saúde, Equidade e Sustentabilidade.

Neste artigo vamos discutir as propostas para o enfrentamento dos problemas das cidades, com base nas pesquisas e projetos já desenvolvidos e encontrados na literatura especializada Brasileira 
e Latino Americana e novas possibilidades existentes em função dos Objetivos do Desenvolvimento Sustentado, agenda da Organização das Nações Unidas (ONU) com a qual nosso país esta comprometido até 2030 .

\section{As Agendas Sociais de Desenvolvimento Urbano: Concepções envolvidas e a experiência brasileira}

Agendas sociais voltadas para o desenvolvimento local têm sido propostas no Brasil a partir dos anos de 1990, com o objetivo de estimular processos e políticas públicas que colaborem para o desenvolvimento local e melhorem as condições de vida e saúde das populações. São exemplos de agendas sociais: a Agenda 21 adotada pelo Ministério do Meio Ambiente e Cidades/Municípios Saudáveis, incentivada pela Organização Pan-americana de Saúde, rede DLIS - Desenvolvimento Local Integrado Sustentável, apoiada pelo governo federal até 2002, mas agora desativada, Cidades Educadoras, Cidades Sustentáveis, Cidades Inteligentes e outras. Essas agendas fazem a interconexão entre o Desenvolvimento Humano/ Desenvolvimento Social, as questões ambientais e a Promoção da Saúde. O Brasil através de seus ministérios, estados e municípios tem desenvolvido vários das agendas sociais mencionadas, mas de uma forma desintegrada e setorial, sem relação umas com as outras, mesmo convivendo no mesmo território e com resultados muitas vezes animadores, mas sem continuidade nas gestões municipais.

\subsection{Mas qual a origem de tudo isto e os apoios institucionais que foram sendo criados?}

Os principais pressupostos do Movimento por Cidades Saudáveis relacionam-se a antigas preocupações do Movimento Sanitário europeu do Século XIX, que já reconhecia os governos locais das cidades e as associações comunitárias como importantes agentes no equacionamento dos problemas de saúde. Algumas pesquisas como a de Mackeown, na Inglaterra (1982) e alguns documentos como o Informe Lalonde (1974), questionaram o papel exclusivo da medicina na resolução dos problemas de saúde. Os impactos dessas pesquisas e desses documentos, naquele momento, foi tão intenso, que se pode afirmar terem dado início a uma nova era de interesse social e político pela Saúde Pública (Westphal, 2007).

De 1974 em diante os contornos do novo movimento são estabelecidos, culminando com uma "proposta inovadora para promover o desenvolvimento das Cidades" - o Projeto Cidades Saudáveis - em 1986. O conceito de Promoção da Saúde, como referência ao movimento, reforça a importância da ação política e ambiental e de uma forma secundária a mudança dos estilos de vida. Entende-se por Promoção da saúde como um processo através do qual os diferentes grupos da população se capacitam para identificar e buscam os meios para conseguir controlar os fatores ou condições que ou favorecem ou dificultam seu bem estar e o da comunidade ou podem estar pondo-a em risco, tornando-a vulnerável ao adoecimento e prejudicando a qualidade de vida de seus habitantes (Ministério da Saúde, 2002).

O movimento por Cidades Saudáveis, foi resultado desse movimento ideológico que eclodiu entre os anos 1980-2000 tendo se transformado em uma agenda urbana de desenvolvimento social, proposta pela Organização Mundial de Saúde e disseminada por todos os países do mundo (OMS). Essa agenda foi criada com o objetivo de estimular a operacionalização de uma nova forma de gestão municipal, motivando autoridades políticas e civis, as instituições públicas e privadas, empresários, trabalhadores e toda a sociedade civil, a dedicar esforços constantes para melhorar as condições de vida, trabalho e cultura da população, estabelecendo uma relação harmoniosa com o meio ambiente, fortalecendo a participação comunitária para melhorar a convivência, desenvolver a solidariedade, a cogestão, a democracia resultando em melhoria da qualidade de vida de populações locais (Bogus \& Westphal, 2007).

A expectativa era que governos, juntamente com a sociedade civil, desenvolvessem estratégias, em diversos setores das políticas sociais, com a implementação de projetos interinstitucionais e intersetoriais, para a melhoria das condições de vida e saúde da população urbana e, portanto, de sua qualidade de vida. As primeiras cidades a implementar foram Toronto no Canadá e 11 Cidades Européias promovendo articulação entre o setor público e o setor privado transformando programas locais de saúde em projetos de desenvolvimento urbano. 
Chegou ao Brasil através de um apoio canadense, mas depois foi adotada e apoiada pela Organização Pan-americana de Saúde, sub-região Brasil e pelo Ministério da Saúde, mas precisava ser adotada por um prefeito interessado em desenvolver a proposta (Westphal, 2007).

\subsection{Que proposta era esta?}

É um projeto de desenvolvimento econômico e social, que objetiva colocar saúde e suas múltiplas determinações como um critério de tomada de decisões no plano do desenvolvimento local. É também um movimento de luta por um estilo de desenvolvimento sustentável, que inclui ações para transformar as relações excludentes, conciliando interesses econômicos e de bem-estar social, condições indispensáveis para obter saúde e desenvolvimento para as cidades, os estados e o país. (Westphal, 2007).

O objetivo estratégico desta proposta era motivar governantes e sociedades para a melhoria das condições de vida e saúde dos diferentes segmentos da população urbana. Para isso foram desenvolvidas metodologias, para o trabalho em diversos setores de políticas sociais - para implementação de projetos estratégicos, interinstitucionais e intersetoriais - e realizar ações em diferentes ambientes, como escolas, unidades de saúde e os territórios de seu entorno, indústrias, espaços de lazer e outros de preferência com um plano de desenvolvimento do município como pano de fundo. Esse conceito, portanto, enfatiza a noção de processo e compromisso compartilhado. Uma cidade não se torna saudável por decreto, a noção de processo longo e contínuo, decisão e vontade política perpassam todo o trabalho individual e coletivo.

Na realidade o significado de "Cidade Saudável" depende da percepção de seus habitantes e das peculiaridades locais - sua história, seus líderes, seus problemas e suas potencialidades e seus compromissos éticos com a equidade, o compromisso das lideranças e da comunidade em geral com a democracia - responsável pelo desenvolvimento da autonomia dos cidadãos e a intersetorialidade que responde a ampla causalidade dos problemas e às potencialidades locais.

Várias estratégias são características deste movimento, que inaugura uma nova forma de gestão municipal planejada a partir de um diagnóstico de problemas e de potencialidades locais. 0 administrador deve se comprometer com a identificação de políticas públicas saudáveis ou melhor promotoras de saúde ou qualidade de vida, para serem desenvolvidas ao logo de um período e a partir de um diagnóstico e um plano de governo para resolver os problemas identificados e aumentar a equidade social. A integração entre os diferentes setores do governo ou melhor as ações intersetoriais são fundamentais para promover o desenvolvimento integrado do município e superação dos problemas.

A idéia de formar redes de cidades saudáveis ou de cidade que desenvolvem agendas sociais pelo desenvolvimento e sustentabilidade tem sido ventilada. As cidades brasileiras, assim como as cidades da América Latina enfrentam questões decisivas, e problemáticas muito semelhantes, como o crescimento demográfico, o peso da desigualdade social, o déficit de infra-estrutura moderna e a existência de governos com tradição política patrimonialista, paternalista e clientelista. Todas essas questões têm influenciado fortemente as condições de vida das populações. Redes de cidades com problemas semelhantes poderiam fortalecer este processo que é potencialmente excelente em termos do seus ideários e seus pressupostos, mas que não deslanchou aqui no Brasil.

Todos seus pressupostos não são fáceis de seguir, pois representam uma grande mudança nas formas de gestão municipal. Desde do ano 2000 vários municípios brasileiros assumiram projetos de Cidades Saudáveis, mas quase nenhum deles deu continuidade aos processos, especialmente depois de mudanças administrativas após eleições (Westphal, 2007).

\section{0 movimento por cidades saudáveis hoje}

Hoje a Rede Européia de Cidades ainda existe, mas a canadense foi perdendo força ao longo do tempo. Na América Latina a Rede Latino Americana de Cidades Saudáveis continua existindo, sendo mais forte no México, Argentina e Chile. O Brasil participa desta Rede através do movimento dos municípios potencialmente saudáveis e com a rede nordestina de municípios saudáveis. 
O movimento por cidades saudáveis, apesar das perdas e ganhos, ainda tem lugar de destaque no final do século XX nas diferentes regiões do mundo e se soma a outros movimentos difundidos por outras agendas sociais, como a Agenda 21, que buscam melhorar a qualidade de vida nos espaços urbanos (Westphal \& Oliveira, 2015).

\subsection{Qual a relação entre o Movimento Municípios Saudáveis e outras agendas sociais que desejam a melhoria da qualidade de vida da população brasileira e de outros países?}

Considerando esses pressupostos o Movimento por Cidades Saudáveis se associa a outros movimentos mundiais que buscam o desenvolvimento social e a sustentabilidade ambiental. A partir do ano 2000, a Organização da Nações Unidas, consegue um acordo entre países membros que resolveram compartilhar uma agenda internacional - os Objetivos do Desenvolvimento do Milênio (ODM), estabelecidos pela Organização da Nações Unidas no ano 2000 para serem atingidos até o ano 2015. Os ODM eram objetivos mensuráveis, acordados universalmente, para combater a pobreza extrema e a fome, prevenir doenças e ampliar o acesso ao ensino primário de qualidade e à saúde materna, entre outras prioridades para o desenvolvimento. Os ODM também conseguiram enormes avanços na luta contra a HIV/AIDS e outras doenças, como a malária e a tuberculose. A existência desses objetivos e o compromisso dos municípios com a sua consecução trouxe esperança de que uma das estratégias adotadas fosse o desenvolvimento de agendas sociais que tivessem um direcionamento para a consecução desses objetivos. Pesquisa realizada nas cinco regiões do país identificou em várias cidades o desenvolvimento do que o Ministério do Meio Ambiente financia e denomina de Agenda 21 e a agenda, objeto desse artigo, denominada de Cidades Saudáveis (Westphal et al., 2011 e Westphal et al., 2013).

Durante a Conferência Rio+20, que ocorreu na cidade do Rio de Janeiro (2012), iniciou-se o processo de discussão para ampliar e resolver alguns problemas que os ODM não tinham dado tanto destaque: adoção de um conjunto de objetivos globais que atendessem à integração social, econômica e ambiental do planeta. Em 2015, na Conferência da ONU sobre Desenvolvimento Sustentável, foi aprovada, por unanimidade pelo países-membro da organização, a Agenda 2030 e os Objetivos de Desenvolvimento Sustentável (ODS), que substituiria a Os Objetivos do Desenvolvimento do Milênio. No mesmo ano, duas conferências internacionais também marcaram o processo de discussão para a implementação dos ODS: Conferência das Partes (COP21), com a aprovação do Acordo de Paris para reduzir o aumento da temperatura global do planeta, e a III Conferência Internacional para o Desenvolvimento, em Adis Abeba, Etiópia, que estabeleceu fluxos de financiamento para políticas com prioridades econômicas, sociais e ambientais (Westphal, Fransceschini \& Setti, 2018).

\subsection{Quais agendas ou propostas nacionais e internacionais poderiam fortalecer 0 desenvolvimento de projetos ou redes de cidades saudáveis, neste momento histórico?}

Os ODS substituem os Objetivos de Desenvolvimento do Milênio, os quais iniciaram no ano 2000, e que foram uma iniciativa global para, principalmente, erradicar a pobreza. Lições valiosas foram aprendidas com os ODM para a formação dos ODS. Hoje estados e municípios, sob a coordenação do governo federal do Brasil, comprometido com a ONU, para a consecução dos objetivos do Desenvolvimento Sustentado, continuam estimulando e cobrando o governo brasileiro a fazer esforços para acabar com a fome, alcançar a igualdade de gênero, melhorar os serviços de saúde, e garantir que todas crianças tenham acesso à escolas de qualidade após o ensino primário. Os ODS também são um chamado para que os habitantes do planeta façam a transição para um futuro mais sustentável.

A Agenda 2030 para o Desenvolvimento Sustentado representa um compromisso ousado para finalizar o trabalho iniciado pelos ODM e abordar os problemas globais mais urgentes. Os 17 Objetivos diferentes são interligados, por que se tem certeza que o êxito de um ODS afeta diretamente outro Objetivo. Uma de suas metas - Combater os efeitos adversos da mudança do clima - deve influenciar diretamente a forma com que os Estados e Munícipios brasileiros gerenciam seus recursos naturais. Alcançar a igualdade de gênero e melhorar a saúde ajudará a erradicar a pobreza. Fomentar a paz e transformar as sociedades em inclusivas reduzirá as desigualdades e contribuirá para que as economias prosperem. A Agenda 2030 e os ODS foram e 
são agora uma oportunidade única em benefício da atual e futuras gerações. Elas constituem estratégias convergentes para o Desenvolvimento Sustentável integrando desenvolvimento e saúde. Espera-se que o governo que se iniciará em 2019 não deixe de lado os esforços realizados até aqui e continue apoiando agendas estaduais e locais para a consecução dos ODS. (cf. Agenda 2030; Westphal, Franceschini \& Setti, 2018).

Os Determinantes Sociais de Saúde constituem hoje uma temática central ao desenvolvimento da saúde, conforme proposta da Assembléia Geral da Organização Mundial de Saúde, a qual pressupõe uma relação indissociável entre o estado de saúde das populações e o grau de desenvolvimento humano de que partilham. No Brasil, após a constituição da Comissão Mundial para o desenvolvimento de estudos sobre os DSS instaurou-se uma Comissão Nacional dos DSS, cujos trabalhos, orientados pela pesquisa em busca de evidências científicas, pela aplicabilidade dos resultados na proposição de ações integradas por maior equidade em saúde no país. Após dois anos de trabalho, obtiveram dados importantes que confirmaram a análise dos DSS como ferramenta para o esclarecimento das relações entre saúde e desenvolvimento e apontam de maneira clara para a necessidade de superação das barreiras ao trabalho intersetorial para a melhoria dos níveis de saúde das populações, uma vez que as ações setoriais da saúde constituem, no modelo Dahlgreen/Whitehead, adotado pela Comissão Nacional (Dahlgreen \& Whitehead, 1991), uma das muitas dimensões da vida em sociedade, da qual emanam ações voltadas ao desenvolvimento social e da saúde (Buss \& Pellegrini Filho, 2007). Importante ver e analisar a Declaração Política do Rio Sobre Determinantes Sociais da Saúde, resultado final de todo esse movimento internacional (WHO, 2011).

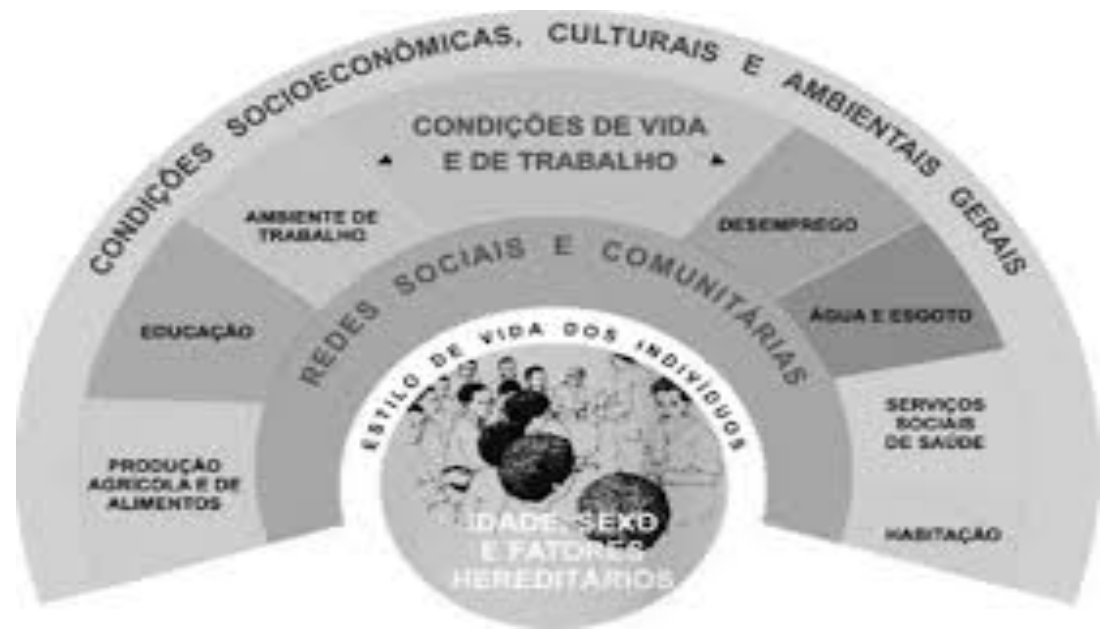

Figura1. Modelo Dahlgreen/ Whitehead dos Determinantes Sociais da Saude. Fonte: Buss \& Pellegrini Filho, 2007

Os ODS pressupõem a realização de ações em todas essas dimensões, as propostas de Agenda 21 muito raramente se restringem à atuação no setor ambiental tradicional, a agenda Cidades Saudáveis propõe ações sobre os DSS, atendendo, portando, o pressuposto da multissetorialidade, e funcionam como fator de proteção da saúde e qualidade de vida das populações envolvidas com seu desenvolvimento. A equidade é a meta entre os países e dentro dos países, pois foi avaliada como a determinante social de maior relevância do processo saúde-doença-cuidado. Há uma relação direta da preocupação com os Determinantes Sociais da Saúde com a proposta de Cidades Saudáveis e todas as outras semelhantes que tenham como objetivo a melhoria da qualidade de vida e saúde da população e a preservação do Meio Ambiente.

\section{Das Cidades Saudáveis as Cidades Sustentáveis}

Duarte (2006) em sua dissertação de mestrado analisou e identificou semelhanças e diferenças e ainda as possibilidades de articulação apresentadas pelas agendas sociais de desenvolvimento local que estavam em andamento naquele época: Cidades / Municípios Saudáveis, Agenda 21 local e Desenvolvimento Local Integrado Sustentável (DLIS). Analisou também as convergências entre elas, o que teria um efeito sinérgico e uma contribuição mais efetiva, portanto em termos de desenvolvimento local. 
O panorama das agendas revelou que processos de DLIS e de Agenda 21 Local apresentavam a época, maior abrangência e podiam ser encontradas em várias cidades de todas as regiões do país. A agenda Cidades/Municípios Saudáveis apresentava menor abrangência e concentrava-se mais nas regiões Sul e Sudeste e nos estados do Ceará e Pernambuco.

A pesquisadora concluiu que um dos fatores que contribuíram para a maior difusão das duas agendas mencionadas foi o apoio que estas agendas obtiveram do Governo Federal. Conforme foi apontado anteriormente, o DLIS passou a ser experimentado em grande escala por meio do Programa Comunidade Ativa, do governo Fernando Henrique Cardoso, a partir de 1999, coordenado pela socióloga Ruth Cardoso, primeira dama do país. No Governo do presidente Luís Inácio da Silva, a partir de 2004, o programa Agenda 21 passou a integrar o Plano Plurianual do Governo Federal PPA 2004-2007 - tornando-se uma das bases para a formulação de políticas públicas estruturais do país no quadriênio 2004/2007. 0 foco da ação local, definido no programa Agenda 21, e a criação de um processo de formação continuada em Agenda 21 local, contribuiu para o surgimento de novos processos de construção de Agenda 21 Locais em todo país. A agenda de Cidades Saudáveis teve o apoio técnico da Organização Pan Americana de Saúde, no início da década de 90, por uns dez a quinze anos ou enquanto havia no Ministério da Saúde a Secretaria de Políticas de Saúde e o Programa de Promoção da Saúde. As Universidades em suas áreas ligadas a área de saúde em vários Estados do país também tiveram experiências importantes relacionadas a essa agenda. Neste período foi fundado na Universidade de São Paulo, Faculdade de Saúde Pública o Centro de Estudos, Pesquisa e Documentação em Cidades Saudáveis (CEPEDOC), hoje Centro Colaborador da Organização de Saúde. A Universidade Estadual de Campinas (UNICAMP) apoiou o projeto Municípios Potencialmente Saudáveis e a Fiocruz também desenvolveu e desenvolve projetos nesta linha no Rio de Janeiro. Podemos afirmar que neste momento a agenda de Cidades Saudáveis está em compasso de espera.

Uma iniciativa que tem alguma potencialidade de ser levada adiante é a relacionada ao programa de Cidades Sustentáveis, apoiado pela Rede Nossa São Paulo, Rede Social Brasileira por Cidades Justas e Sustentáveis, Instituto Ethos de Empresas e Responsabilidade Social com apoio da Fundação Avina Instituto Arapyau. A grande motivação é o desenvolvimento sustentável e o referencial teórico os Objetivos do Desenvolvimento Sustentável da Organização das Nações Unidas, a qual o Brasil é signatário.

As agencias apoiadoras oferece às cidades interessadas, na pessoa de seus prefeitos e partidos políticos ferramentas de apoio às cidades que assumirem o compromisso com a consecução dos "Objetivos do Desenvolvimento Sustentado". Os prefeitos devem assinar uma carta compromisso com os ODS.

Em troca as cidades participantes recebem benefícios das entidades promotoras tais como visibilidade em materiais de divulgação e nos meios de comunicação, têm acesso a informações estratégicas, trocam experiências com outros municípios, além de se constituírem como referências exemplares de desenvolvimento sustentável.

Os signatários da Carta-Compromisso ou da Carta de Adesão também podem utilizar o selo Cidade Participante do Programa Cidades Sustentáveis em suas publicações, além de estarem aptos a se inscreverem ao Prêmio Cidades Sustentáveis. Há possibilidade de obtenção de mapa com os municípios signatários (Programa Cidades Sustentáveis, 2012).

Em nossa opinião é mais uma iniciativa que não incorpora técnicos e cientistas que já tem ou tiveram experiências na área e que poderiam colaborar para o êxito desta proposta.

\section{Conclusão}

As Cidades Saudáveis uma agenda de desenvolvimento ligada a Promoção da Saúde (PS), como alternativa de modelo de atenção à saúde, foi desenvolvida no Brasil sob influência de propostas internacionais e do movimento de Saúde Coletiva/Reforma Sanitária na concepção e institucionalização do Sistema Único de Saúde (SUS). 
A Promoção da Saúde como área de conhecimentos e práticas no SUS percorreu um longo caminho, até hoje - quase 20 anos - para se afirmar como Política Nacional de Promoção da Saúde (PNPS), ampliando suas possibilidades de atuação em relação à integralidade do cuidado a saúde, e em relação à determinação social do processo saúde-doença. Malta et al. (2016 p.1684) afirmam que este processo ocorreu em três períodos: (1) 1998/2004 denominado o "Embrião da Promoção da Saúde"; (2) 2005 a 2013 onde "nasceu, cresceu e se desenvolveu uma PNPS"; (3) 2013-2015 "revisando, ampliando e divulgando a PNPS". Nesse último período aconteceu uma revisão na política, mas que não deu maior importância a proposta de Cidades Saudáveis.

No governo que se inicia os professores de universidade ligados a área de conhecimentos da Promoção da Saúde e os experientes no desenvolvimento dos projetos de Cidades Saudáveis podem se colocar a disposição para colaborar na implementação do Projeto Cidades Sustentáveis ou reacender a chama do Projeto Cidades Saudáveis.

\section{Referências}

Agência Brasil (2017). Desigualdade na América Latina segue em ritmo muito alto, diz Cepal. Disponível em: <http://agenciabrasil.ebc.com.br/internacional/noticia/2017-05/desigualdade-na-america-latina-segueem-ritmo-muito-alto-diz-cepal>. Acesso em 27 set. 2018.

Agenda 2030. Disponível em: <https://nacaesunidas.org/pos2015/agenda2030>. Acesso em 27 set. 2018.

Brasil, Ministério da Saúde. (2002). Secretaria de Políticas de Saúde. Projeto Promoção da Saúde. As Cartas da Promoção da Saúde/ Ministério da Saúde, Secretaria de Políticas de Saúde, Projeto Promoção da Saúde - Brasilia: Ministério da Saúde.

Bogus, C. M., \& Westphal, M. F. (2014). Participação social e cidadania em movimentos por cidades saudáveis In: J.C.A. Fernandes, \& R. Mendes. Promoção da Saúde e Gestão Local (2a. ed.). São Paulo: Hucitec, Cepedoc Cidades Saudáveis.

Buss, P. M., \& Pellegrini Filho, A. A. (2007). Saúde e seus determinantes sociais physis: Saude Coletiva, Rio de Janeiro, 17(1):77-93.

Duarte, M. F. (2006) Agendas sociais brasileiras de desenvolvimento local: possibilidades de diálogo, articulações e de convergência. Dissertação de mestrado apresentada ao Programa de Pós-Graduação em Saúde Pública da Universidade de São Paulo. São Paulo, SP, Brasil.

Malta, D. C. et al. (2016). Política Nacional de Promoção da Saúde (PNPS): capítulos de uma caminhada ainda em construção. Ciência Saúde Coletiva, Rio de Janeiro, 21(6) pp. 1683-1694.

Minowa, E. et al. (2017) Contribuição das universidades na revisão da Política Nacional de Promoção da Saúde: Saude Soc., São Paulo 26(4): 973-986.

Programa Cidades Sustentáveis (2012). Programas Cidades Sustentáveis (5a. ed.). Recuperado de: <http:// fm.usp.br/biblioteca/conteudo/biblioteca_229_publicacao-programa-cidades-sustentaveis.pdf>.

Westphal, M. F., Mendes, R., \& Comaru, F. A. (2006). A Promoção da saúde e as cidades. In: A. Castro, \& M. Malo. SUS: Ressignificando a Promoção da Saúde (pp. 133 a 151). São Paulo: Hucitec, OPAS.

Westphal, M. F., \& Oliveira, S. C. (2017). Mobilidade, equidade e Promoção da Saúde na cidade. In: B.R. Soares et al.. Construindo Cidades Saudáveis: utopias e práticas (MG). Uberlândia: Assis Editora.

Westphal, M. F. (2007). Equidade no acesso e cidades saudáveis. In: J. Marcovitch (org.). Crescimento Econômico e distribuição da renda: prioridades para a ação (pp. 89-106). São Paulo: Edusp, Editora Senac São Paulo.

Westphal, M. F., \& Oliveira, S. C. (2015). Cidades Saudáveis: uma forma de abordagem ou uma estratégia de ação em Saúde urbana? Revista da Usp, 107: 91-104, outubro/novembro/dezembro. 
Westphal, M. F., Fernandez,J. C., \& Nascimento, P. R. (2013). Práticas democráticas participativas na construção de agendas sociais de desenvolvimento em municípios do sudeste brasileiro. Ambiente \& Sociedade, São Paulo 12(2):103-128, abr./jun.

Westphal, M. F., Zioni, F., Almeida, M. F., \& Nascimento, P. R. (2011). Monitoring Millenium development goals in Brazilian Municipalities: Challenges to be et in facing up to inequities. Cad Saúde Pública, Rio de Janeior, 27sup S155-S163, 2011.

Westphal, M. F., Franceschini, M. C., \& Setti A. F. F. (2018) How can Healthy Municipalities, cities and Communities Strategy advance Sustainable Development Goals Agenda? Lessons from Agenda 21 and the MDGs in Brazil. In: U. Azeiteiro, M. Akerman, W. Leal Filho, A. Setti, \& L. Brandli (eds.). Lifelong learning and Education in Healthy and Sustainable cities (pp. 265-272). World Sustentability Series. Springes, Cham.

Wikipedia (2018). Produto Interno Bruto do Brasil. <https://pt.wikipedia.org/wiki/ Produto_interno_bruto_do_Brasil\#cite_note-30>. Acesso em 13 dez. 2018.

Whitehead, M. (1990). The concepts and principles of Equity anda Health. Copenhagem: World Health Organization.

World Health Organization - WHO (2011). Declaração Política do Rio sobre Determinantes Sociais da Saúde. In: World Conference on Social Determinants of Health. Rio de Janeiro: WHO, 2011. Disponível em: <https://www.who.int/sdhconference/declaration/Rio_political_declaration_portuguese.pdf>. Acesso em 30 set. 2018 . 